\title{
Testis development and spermatogenesis in drones of the honey bee, Apis mellifera $\mathrm{L}$.
}

\author{
Denyse C. Lago ${ }^{1}$, Juliana R. Martins ${ }^{1,2}$, Rodrigo P. Dallacqua ${ }^{3,4}$, \\ Douglas Elias SANTOS ${ }^{5,6}$, Marcia M. G. Bitondi ${ }^{7}$, Klaus HartFeldER ${ }^{5}$ \\ ${ }^{1}$ Programa de Pós-Graduação em Genética, Faculdade de Medicina de Ribeirão Preto, Universidade de São Paulo, Av. \\ Bandeirantes 3900, Ribeirão Preto, SP 14049-900, Brazil \\ ${ }^{2}$ Instituto de Ciências Biomédias, Departamento de Biologia Celular e do Desenvolvimento, Universidade Federal de \\ Alfenas, Rua Gabriel Monteiro da Silva 700, Alfenas 37130-001 MG, Brazil \\ ${ }^{3}$ Programa de Pós-Graduação em Biologia Comparada, Faculdade de Filosofia, Ciências e Letras de Ribeirão Preto, \\ Universidade de São Paulo, Av. Bandeirantes 3900, Ribeirão Preto, SP 14040-901, Brazil \\ ${ }^{4}$ Setor de Biologia Geral, Instituto de Biociências, Universidade Federal de Mato Grosso do Sul, Av. Costa e Silva, s/nº, \\ Campo Grande, MS 79070-900, Brazil \\ ${ }^{5}$ Departamento de Biologia Celular e Molecular e Bioagentes Patogênicos, Faculdade de Medicina de Ribeirão Preto, \\ Universidade de São Paulo, Av. Bandeirantes 3900, Ribeirão Preto, SP 14049-900, Brazil \\ ${ }^{6}$ Laboratório Regional de Iporá - SANEAGO, Av. 24 de Outubro 1, Iporá 76200-000 GO, Brazil \\ ${ }^{7}$ Departamento de Biologia, Faculdade de Filosofia, Ciências e Letras de Ribeirão Preto, Universidade de São Paulo, Av. \\ Bandeirantes 3900, Ribeirão Preto, SP 14040-901, Brazil
}

Received 30 July 2019 - Revised 19 January 2020 - Accepted 14 April 2020

\begin{abstract}
Like Apis mellifera queens and different from all other bees, drones also have an exaggerated gonad phenotype, with over 150 serial units in each gonad. Yet, compared with the ovaries of the female castes, little is known about the development of the honey bee testis. Here we present a histological atlas on postembryonic testis development and spermatogenesis. Already in the first instar larvae, the testioles composing each testis can be distinguished. The testioles then grow along their apical-basal axis by mitotic divisions of the spermatogonia, which eventually form germ cell clusters. Meiosis starts when brood cells are capped, and it ends with the appearance of spermatids in red-eyed pupae. Subsequently, spermiogenesis takes place, and all spermatozoa are formed before adult emergence. We also present the first data on juvenile hormone levels in drone larvae. With this, we provide a database for future research on gonad development in honey bee drones.
\end{abstract}

\section{honeybee / drone / testis development / germ cell / spermatogenesis}

\section{INTRODUCTION}

Honey bees, leaf cutter and army ants, and wasps of the genus Vespula stand out among all the social Hymenoptera in terms of their extraordinarily high-effective queen mating

Corresponding author: K. Hartfelder,

klaus@ fmrp.usp.br

Manuscript editor: David Tarpy frequencies and quantities of sperm produced by the males (Boomsma and Ratnieks 1996; Kronauer et al. 2004), indicating strong selection on male sexual traits (Boomsma et al. 2005; Stürup et al. 2013). Yet, males are also considered the neglected gender (Koeniger 2005), not only in honey bees but also in social Hymenoptera in general. Hence, drones clearly deserve a closer look, due to their importance in honey bee mating biology (see recent review by Koeniger et al. 2014a) and 
bee breeding strategies by natural or instrumental insemination (Koeniger et al. 2014b).

The reproductive biology in the genus Apis is replete of peculiarities: a virgin queen mates sequentially with multiple drones high up in the air, the drones die during copulation, the mating sign of the previous drone is immediately removed by the next copulating drone, and each drone can inject over a million spermatozoa into a queen's reproductive tract (Koeniger et al. 2005; Baer 2005). Thus, honey bee queens are highly polyandrous, with mean mating frequencies ranging between 15 and 25 (Adams et al. 1977; Kraus et al. 2005; Tarpy et al. 2015). Furthermore, just like the queen's ovaries, the drone's testes are composed of a large number of serial units -150 and more testiolar tubules per testis (Zander 1916; Hoage and Kessel 1968). In this respect, they differ from the males of all other bee species, which generally have only four testiolar tubules per testis (Ferreira et al. 2004). With regard to these reproductive traits, the genus Apis as a whole, stands in contrast to all the other bees, even to the equally highly eusocial stingless bees, Meliponini, which, with few exceptions, are monandrous (Vollet-Neto et al. 2018). Also, due to the high number of testiolar tubules, A. mellifera drones are capable of producing roughly 10 times more sperm than the males of stingless bees, and 100 times more than bumble bee males (Garófalo 1980).

In a previous review on the ovary dimorphism in the female castes of the honey bee (Hartfelder et al. 2018), we put forward the hypothesis on a male-driven origin of the exaggerated gonad morphologies in the two sexes. The hypothesis was based on the gonadal architecture shared between queens and drones, and on the fact that in insects in general, mechanisms underlying gonad development are shared between the sexes (Büning 1994; Green II and Extavour 2012). We furthermore considered that there should be strong selection pressure on sperm production in honey bee drones.

The argument is based on two reasons. First, all sperm are produced during a relatively short temporal window during preimaginal development, as by the end of the pharate-adult phase, practically all spermatozoa are formed and ready to migrate from the testes to the seminal vesicles during the first days after adult emergence (Bishop 1920; Louveaux 1977; Koeniger et al. 2014a). The seminal vesicles are enlarged receptacles in the vasa deferentia of the drone reproductive tract. Second, the comparison of sperm counts in a drone's seminal vesicles (Schlüns et al. 2003) with those in a queen's spermatheca indicates that only about $2.5 \%$ of the sperm received by a queen during her mating flight(s) will end up in the spermatheca (Baer 2005). The large majority will be dumped from her genital tract. While plausible from a theoretical point of view, speculating on possible selection pressure and evolutionary processes nevertheless requires that we understand the basics concerning testis development and spermatogenesis in honey bee drones.

The most comprehensive descriptions on spermatogenesis (Meves 1907) and testis development (Zander 1916) date back by over 100 years, and as these are in German, they are not readily accessible to most bee researchers. In English, a brief description on testis development is given by Snodgrass (1956), primarily based on the work by Meves (1907) and taken from a short paragraph in Nelson (1924). With respect to spermatogenesis, a critical issue has always been the question of how meiosis, especially the first meiotic division, is modified in the haploid males of the Hymenoptera. For honey bee drones, the outstanding transmission electron microscopy study by Hoage and Kessel (1968) has shed much clarity on this matter. Other electron microscopy studies provided detailed insights on sperm morphology (CruzHöfling et al. 1970; Lensky et al. 1979; LinoNeto et al. 2000). All this information has been compiled by Cruz Landim (2009) in her book on the morphology of bees. However, we found that a detailed description on the dynamics of testis development and spermatogenesis in the honey bee drone was still lacking.

In the current study, we provide a detailed description on testis development and spermatogenesis events based on histological sections. The description starts with the first-instar larvae and follows all the subsequent stages of larval and pupal development until the pharate-adult stage, shortly before adult emergence. We describe both the overall architecture of the testis and of the 
testiolar tubules, and we provide information on the timing of the mitotic and meiotic phases of spermatogenesis. For insights on possible regulatory mechanisms, we also performed a radioimmunoassay analysis measuring the juvenile hormone $(\mathrm{JH})$ levels in the larval stages of honey bee drones. These can now be directly compared with the $\mathrm{JH}$ levels in queens and workers (Rembold 1987; Rachinsky et al. 1990). In these, JH plays a crucial role in caste determination during the fourth and early fifth larval instars by protecting the queen's larval ovary from degeneration by massive programmed cell death (Schmidt Capella and Hartfelder 1998).

\section{MATERIALS AND METHODS}

\subsection{Collection of drone larvae and pupae}

Drone larvae, pupae, and pharate adults were obtained from three hives of Apis mellifera hybrids (Africanized honey bees) kept in the experimental apiary of the University of São Paulo in Ribeirão Preto, SP, Brazil. Upon removal from their brood cells, the larvae and pupae were classified according to developmental stage (de Oliveira Tozetto and Engels 2013). Larvae from the first to the early fifth larval instar were identified by body weight and head capsule size. The fifth larval instar (L5), which is much longer than the previous ones, was subdivided in nine phases, comprising three feeding phases (L5F1, L5F2, L5F3) based on weight classes, three spinningstage phases (L5S1, L5S2, L5S3), characterized by progressive voiding of the gut, and three prepupal phases (PP1, PP2, PP3), characterized by progressive eversion of the pupal hind legs beneath the larval cuticle. Pupae were classified according to progressive eye coloration, white $(\mathrm{Pw})$, pink $(\mathrm{Pp})$, and dark $(\mathrm{Pd})$, followed by the pharate-adult stages, where the body gradually becomes melanized from light (Pdl) to intermediate $(\mathrm{Pdm})$, and finally to fully pigmented (Pdd). The same criteria are also used for staging preimaginal honey bee queens and workers (Rembold et al. 1980; Rachinsky et al. 1990). The larvae, pupae, and pharate adults were dissected in physiological saline to remove the testes, which were then cleaned by means of forceps from adhering fat body and transferred to fixative. For histological sectioning, testis pairs were dissected from 5 to 10 individuals per developmental stage and fixed. Those presenting the best preservation (3-5 per developmental stage) were then processed for histology. For the whole mount preparations, another 5-10 testis pairs were dissected per developmental stage and fixed.

\subsection{Macroscopic testis preparation and histological sectioning}

For macroscopic preparations, testes were fixed for $2 \mathrm{~h}$ in glutaraldehyde $(2.5 \%$ in $0.1 \mathrm{M}$ cacodylate buffer containing $0.3 \mathrm{M}$ sucrose), then washed twice in $0.1 \mathrm{M}$ phosphate-buffered saline (PBS), and stored in PBS at $4{ }^{\circ} \mathrm{C}$ until image acquisition.

For histological sectioning, the testes-or whole larvae for the first and second instars - were fixed in paraformaldehyde (4\% in $0.1 \mathrm{M}$ phosphate buffer, $\mathrm{pH} 7.4$ ) at $4{ }^{\circ} \mathrm{C}$ for $16-$ $24 \mathrm{~h}$. Thereafter, they were washed in phosphatebuffered saline (0.1 M, pH 7.4), dehydrated in an ascending ethanol series, and embedded in methacrylate resin (Historesin, Leica), following the manufacturer's instructions. Testes were embedded in individual blocks, and care was taken to orient them so that sagittal sections would be obtained. After polymerization, the blocks were sectioned at $4-\mu \mathrm{m}$ thickness. Serial sections were mounted on microscope slides, dried and stained with methylene blue $(0.125 \%$ in $1 \%$ sodium tetraborate buffer, $\mathrm{pH}$ 9.5) for $5 \mathrm{~min}$, rinsed in tap water, and cover slipped in Entellan (Merck).

\subsection{Image acquisition and processing}

Whole testis preparations were transferred to a drop of PBS in a convex microscope slide and photographed at a fixed magnification setting in a Discovery.V12 SteREO microscope (Zeiss) equipped with an Axiocam MRc5 digital camera system (Zeiss). Histological images were captured in a digital light microscope (Scanscope, OlympusBX61VS), or an AXIO Imager.Z2 light microscope (Zeiss) equipped with an Axiocam MRm digital camera system (Zeiss). The digital images, both for the whole testis preparations and 
the histological sections, were processed in Image $\mathrm{J}$ version Fiji-win64 (NIH, public domain) for adjustment of brightness, contrast, and color hue, before compiling them into figure panels using Adobe Photoshop version CC-2017. Magnification scales were imported directly from the respective camera settings.

\subsection{Juvenile hormone radioimmunoassay}

Larvae were sampled from brood frames of a single colony. Hemolymph was collected from the dorsal vessel of the larvae, and 8-10 $\mu \mathrm{L}$ aliquots of clear hemolymph were immediately transferred to glass vials containing $0.5 \mathrm{~mL}$ of HPLC-grade acetonitrile (Mallinckrodt-Baker). The vials were sealed and stored at $-20{ }^{\circ} \mathrm{C}$ until $\mathrm{JH}$ extraction. The procedure for hemolymph collection and the respective juvenile hormone radioimmunoassay (JH-RIA) protocol are described in detail in Hartfelder et al. (2013). For each of the larval stages, we analyzed five independent biological samples. Due to the small size of the young larvae, each L1 sample consisted of hemolymph taken from 8 to 10 larvae, each L2 sample of 3-5, and each L3 sample of 2 larvae. For all the subsequent stages, single larvae were bled per sample. The data were analyzed in GraphPad Prism software by one-way ANOVA followed by Tukey's multiple comparisons tests.

\section{RESULTS}

\subsection{Position and growth dynamics of the honey bee testis}

The position of the larval honey bee testes and their orientation with respect to the major body axes are schematically illustrated in Figure 1. Their overall growth dynamics from the third larval instar until the pharate-adult stage are shown in Figure 2. The first and second larval instar testes are not shown in this figure, as they are still very fragile and cannot be integrally separated from the surrounding fat body. The testes of third and fourth instar drone larvae (Figure 2a, b) are very similar in structure, size, and position to a larval ovary. Also like the female gonad, each testis is covered by a fine tracheal network, which, during dissection, makes the gonads easily distinguishable from the surrounding fat body. In these early larval stages, the testis is still transparent in appearance.

During the feeding stage of the fifth instar, the testes grow considerably in overall size (Figure 2c, d). This growth continues throughout the cocoon-spinning phase (Figure 2e), until the early pupal stage (Figure 2f). During this period of growth, the peritoneal sheath covering the testis is very fragile, transparent, and ruptures easily during preparation, permitting to see how the testiolar tubules are tightly packed within the testis (Figure $2 \mathrm{~d}-\mathrm{f}$ ). A white spot is visible at the apical end of each testiolar tubule (Figure 2f), possibly representing the apical cap seen in histological sections. During the pharate-adult stage, the peritoneal sheath becomes more resistant and the testes gain in compactness. The slightly brown coloration of the late pupal and pharate-adult testis shown here (Figure $2 \mathrm{~g}, \mathrm{~h}$ ) is not natural, but a result of the fixation process with glutaraldehyde, because upon preparation, they are just as white as the larval ones. The vas deferens, which is of mesodermal origin, connects the testis to the genitalia that are of ectodermal origin (Cruz Landim 2009). This duct ruptures during testis dissection, but its position in the middle of the basal side of the testis is clearly visible in Figure $2 \mathrm{~g}$.

\subsection{Testis architecture in the larval stages prior to the onset of metamorphosis}

Sagittal and horizontal sections of entire first instar larvae (L1) revealed the banana-shaped testes located in the 7th to 9th body segment, in the space dorsal to the midgut and just below the dorsal vessel (Figure 3a, b). At this earliest larval stage, the testiolar tubules are still short, consisting of only a few cells, but the individual tubules are already separated, indicating that the basic testis architecture with the full number of testiolar tubules is established already earlier, during embryonic development.

In the second (L2) (Figure 3c, d) and third (L3) larval instar (Figure $3 \mathrm{e}, \mathrm{f}$ ), the testes grow in apical-basal diameter due to elongation of the testiolar tubules. These tubules are now clearly separated from one another by interstitial cells that 


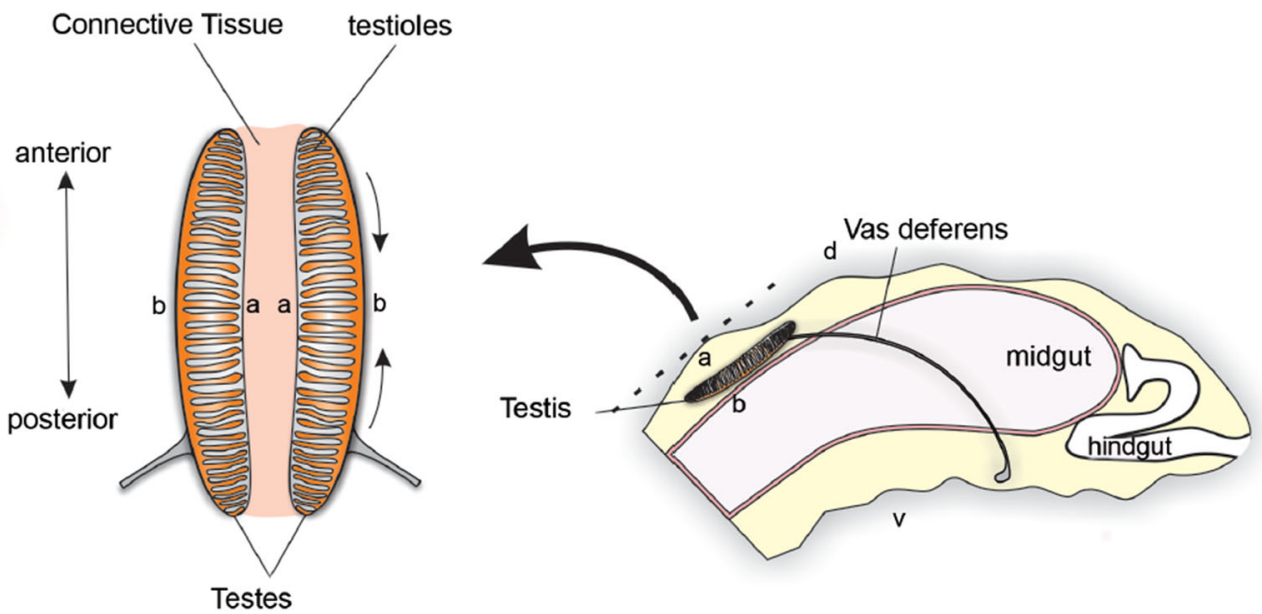

Figure 1. Schematic drawing illustrating the position of the larval testes dorsally (d) to the intestine, as well as the apical-basal orientation of the testiolar tubules. Along the dorsal midline of the larva, the paired testes are connected to each other by connective tissue. Abbreviations: a, apical; b, basal; d, dorsal; v, ventral.
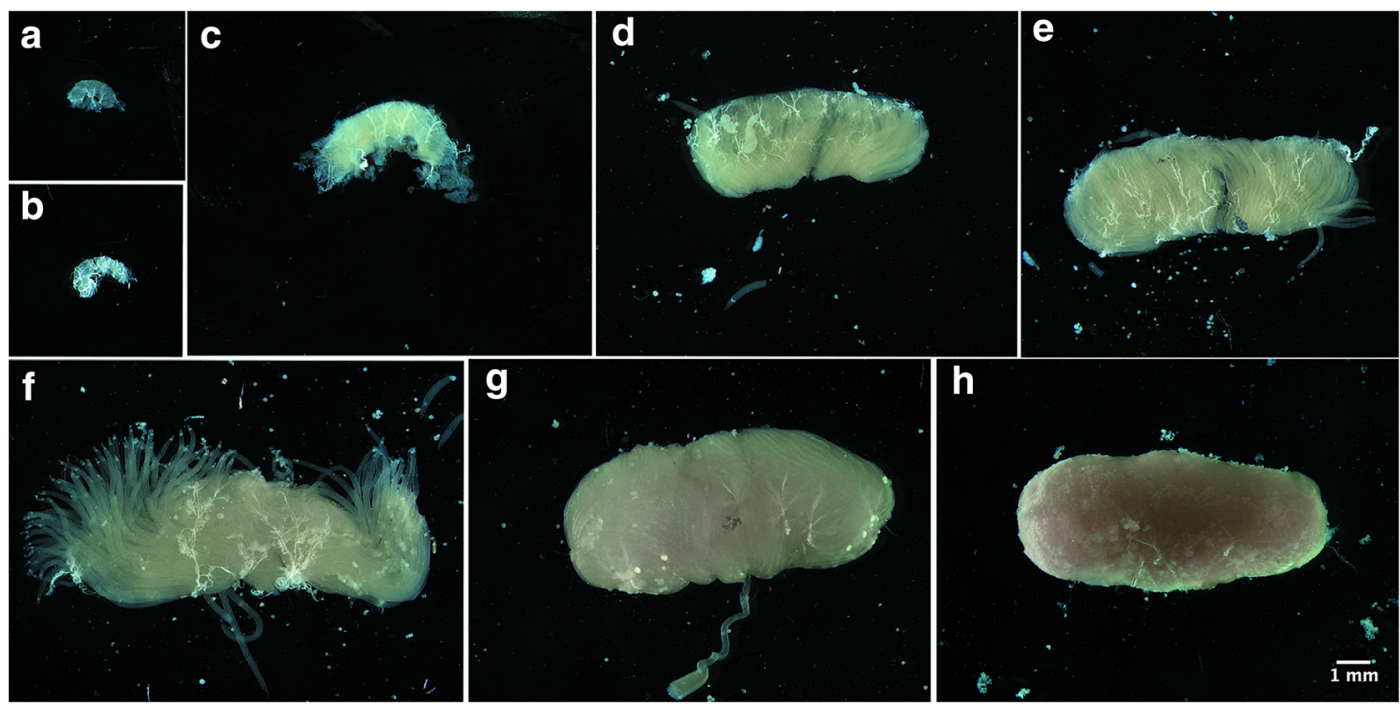

Figure 2. Overview of gonad development in honey bee drones from the third larval instar until the end of the pharate-adult stage. a and b Testis of a third (L3) and fourth instar (L4) drone larva, respectively. $\mathbf{c}$ Testis of an early fifth instar larva (L5F1). d Testis of a fifth instar drone larvae at the end of the larval feeding phase (L5F3). e Testis of a mid spinning-phase drone larvae (L5S2). f Testis of an early pupal-phase drone (Pp), with long testiolar tubules spreading through the peritoneal sheath that has ruptured at the dorsal side during dissection. A small white spot is visible at the apical end of each testiolar tubule. $\mathrm{g}$ Testis of a late pupal-stage drone (Pd); the vas deferens is shown emerging from a mid position at the basal side of the testis. $\mathbf{h}$ Testis of a pharate-adult drone (Pdm). Orientation in all images is with the apical side of the testis to the top. A dense tracheal network surrounding the testis is visible in most preparations, as well as some adhering fat body cells. The testis images for the developmental stages were all captured at the same magnification setting. The scale bar shown in $\mathbf{h}$ applies to all images. 


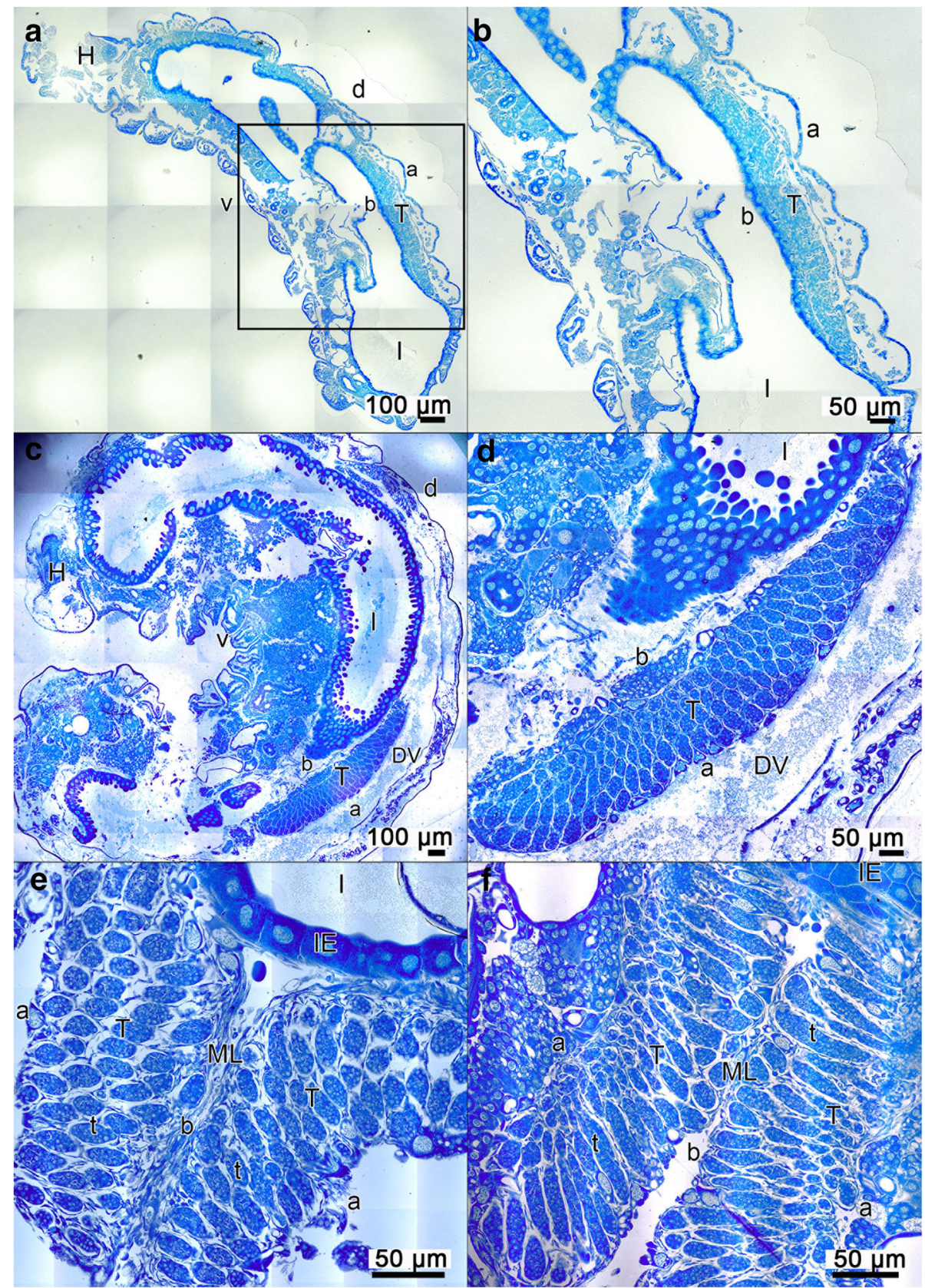

Figure 3. Testis architecture in the early larval instars. a Sagittal section of an entire first instar (L1) drone larvae, with the head oriented to the upper left; high resolution scanning of the section resulted in the 20 image segments represented in this figure. $\mathbf{b}$ Magnified view of the square indicated in a, showing a testis in the space between the intestine and the dorsal vessel in the 7th-9th body segment. $\mathbf{c}$ and $\mathbf{d}$ Sagittal section of a second instar larva (L2) showing that the testis has grown in height along the apical-basal axis and that testiolar tubules are now clearly separated from one another (d is a magnified image of the testis shown in $\mathbf{c}$ ). $\mathbf{e}$ and $\mathbf{f}$ Horizontal sections of the third instar (L3) larvae showing the paired testes aligned along the dorsal midline. Abbreviations: a and b, apical and basal sides of testis, respectively; $\mathrm{d}$ and $\mathrm{v}$, dorsal and ventral sides of the larva; DV, dorsal vessel; $\mathrm{H}$, head; I, intestine; IE, intestinal epithelium; ML, dorsal midline; $\mathrm{T}$, testis; $\mathrm{t}$, testiolar tubule. 
eventually will form an inner peritoneal sheath covering each tubule (Figure 3e, f). In the L3 stage, the tubules acquire a club-shaped form with a rounded and broad apical tip and a narrow basal stalk (Figure 3e, f).

In the fourth instar (L4) testes (Figure 4a, b), the external peritoneal sheath (ps) is a multilayer cover that surrounds all the club-shaped testiolar tubules. At the basal side, the testis-associated proximal vas deferens (pvd) becomes clearly discernible as a longitudinal duct (Figure 4a). In enlarged images of testiolar tubule sections, spermatogonial clusters are seen as distinctly separated from one another (Figure 4b). They are generated by incomplete mitotic divisions that occur in synchrony in the clusters at different positions

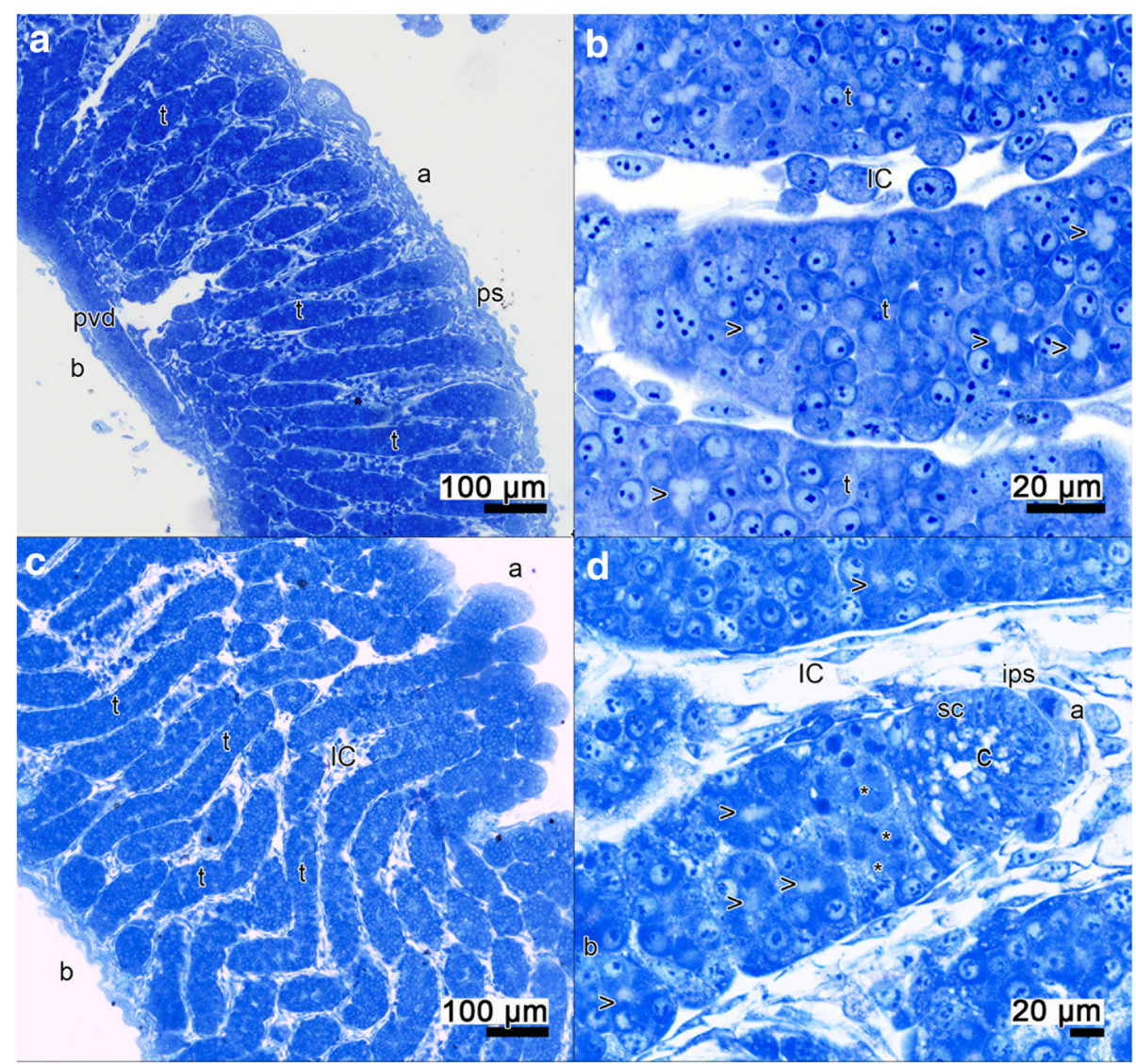

Figure 4. Testis architecture in the fourth (L4) and early fifth-instar feeding phase larvae (L5F1). a General overview and detail of an L4 testis that has considerably grown in height and is covered by a peritoneal sheath. At the basal side, the testiolar tubules are anchored in a longitudinal duct that represents the proximal vas deferens. $\mathbf{b}$ Enlarged image of longitudinally sectioned testiolar tubules of an L4 testis, showing spermatogonial clusters organized as rosettes around their central polyfusomes (arrowheads). c In the L5F1 phase, the testiolar tubules underwent further growth and became curved inside the testis. During dissection, the weak peritoneal sheath had ruptured at the apical side, revealing individual testiolar tubules. d Longitudinal section of the apical tip of an L5F1 testiolar tubule showing the apical cap formed by irregularly shaped somatic cells. Immediately below the cap, individual spermatogonia can be seen (asterisks). These undergo incomplete mitotic division resulting in germ cell clusters that are held together by a central polyfusome (arrowheads). Interstitial cells between the tubules begin to form the respective inner peritoneal sheaths. Abbreviations: $\mathrm{a}$ and b, apical and basal sides of testis, respectively; $\mathrm{c}$, apical cap; IC, interstitial cells; ips, inner peritoneal sheath; ps, peritoneal sheath; pvd, proximal vas deferens; $\mathrm{t}$, testiolar tubule. 
along the apical-basal axis of the testioles. These clusters are held together by intercellular bridges that form a central polyfusome (Figure 4b).

With the next molt, the larva enters the last, fifth instar (L5), which has the longest duration of all larval instars and is divided into three major phases. In the feeding phase (L5F), the larvae are still undergoing major growth while being fed by nurse bees. A general overview of the architecture of a testis of a newly molted L5-stage drone larva (L5F1) is represented in Figure 4c. The testiolar tubules are by now so much elongated that they appear curved around each other. The image in Figure $4 \mathrm{~d}$ shows the apical end of a testiolar tubule with a cap structure consisting of flattened somatic cells and a group of cells in the center with a barely stained cytoplasm. Basally, this cap structure appears clearly separated against the germ cell region. This apical region likely contains germline stem cells and cystoblasts, the latter being the result of unequal divisions of germline stem cells. On leaving the cap region, the cystoblasts undergo sequential mitotic divisions forming early spermatogonia, and these have strongly stained and condensed nuclei. Already at about two cell rows below these cystoblasts, small spermatogonial clusters are visible, and in cross sections, a clear central fusome surrounded by 5-7 spermatogonia can be seen. Hence, the progressive growth in testiolar tubule length appears to be primarily driven by the successive divisions of germline stem cells and the incomplete mitotic divisions that form more and more rows of spermatogonial clusters.

Testis development in the two subsequent phases (L5F2 and L5F3) is illustrated in Figure 5. The images for an L5F2 testis (Figure 5a-c) show the now even more elongated and curved testiolar tubules (Figure 5a). In their overall architecture, they are still very similar to the testioles seen in the L5F1 stage, and cross sections (Figure 5b) show that the spermatogonial clusters are now well separated from each other by an envelope consisting of flattened somatic cells. At their apical ends (Figure 5c), below the apical cap, spermatogonial clusters are still formed by mitotic divisions.

In the last larval growth stage (L5F3), the testiolar tubules appear to have grown even further in length (Figure 5d-f), and the inner peritoneal sheath formed by flattened somatic cells now entirely covers the testioles (Figure 5e, f). Also, more distinct is now the epithelial envelope that surrounds each germ cell rosette (Figure 5e). Inside these rosettes, the spermatogonia appear to have lost their rounded shape. They look more triangular or hexagonal and appear more detached from one another. The apical cap of the testioles is still clearly distinct (Figure $5 \mathrm{f}$ ), but beneath the cap, the number of cystoblasts seems to have diminished, meaning that fewer new germ cell rosettes are now likely to be generated.

A summary schematic representation of testis development in the early larval stage testis is shown in Figure 6. The testes, located dorsally in the 7 th and 8th body segment right above the midgut, are shown with a full set of wellseparated testiolar tubules (Figure 6a). While the testes gradually grow in size by elongation of the testiolar tubules, the inner organization of these tubules also undergoes a change from the early instars (L2-L4) to the fifth instar (L5). During these stages, spermatogonial clusters are formed by successive mitotic divisions (Figure $6 \mathrm{~b}$ ). These clusters then acquire a germ cell rosette architecture, where the spermatogonia surround a central polyfusome that keeps them clustered together (Figure 6c).

\subsection{Testis architecture in the metamorphosis stages of the last larval instar}

Feeding and growth of the larva ceases once the workers cap the brood cell, which marks the onset of the cocoon-spinning phase (L5S). During this phase, the larva also inverts its position in the brood cells and voids the gut. Once this is concluded, it enters the prepupal phase (PP), during which, the pupal cuticle is gradually formed beneath the larval cuticle. The fifth instar then ends with the ecdysis of the whiteeyed pupa $(\mathrm{Pw})$.

In the early spinning phase (L5S1), the shape change of the germ cells that had started already in the L5F3 testioles became more evident (Figure 7a,b). The triangular germ cells now point with their tips towards the central polyfusome (Figure 7c).The electron microscopy images 


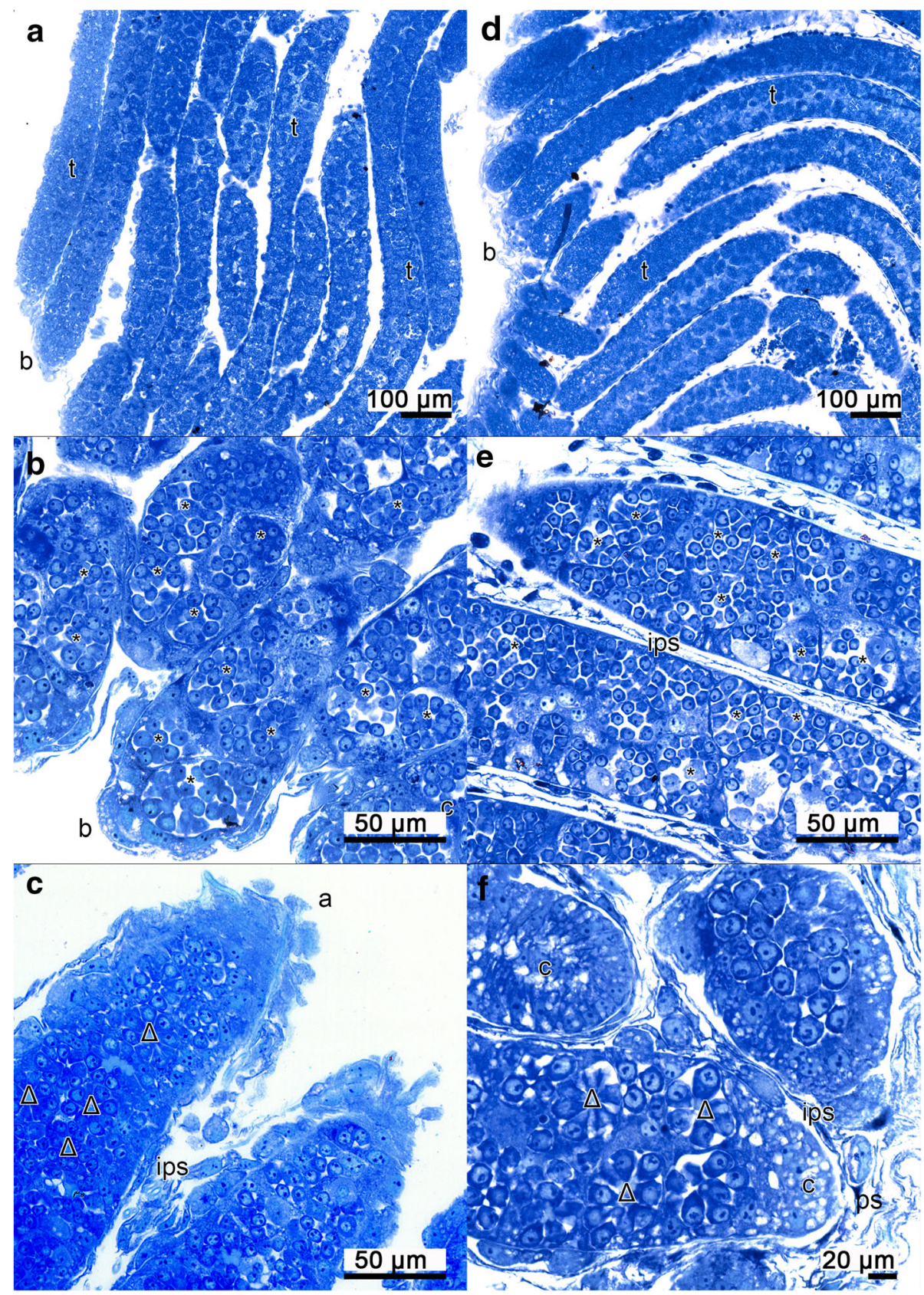

Figure 5. Testis architecture in the fifth instar feeding-stage larvae. a-c Sections of L5F2-stage testes. $\mathbf{d}-\mathbf{f}$ Sections of L5F3-stage testes. a Elongated testiolar tubules twisted inside the testis. b Cross section of testioles showing spermatogonial clusters (asterisks) that are well separated from one another by an envelope of flattened somatic cells. c Apical end of testiolar tubules showing small spermatogonial clusters below the apical cap; triangles indicate their polyfusomes. d Overview of the elongated testiolar tubules. e Somatic cells form the inner peritoneal sheath covering each testiole, and also form an epithelial cover that surrounds and separates the now large germ cell rosettes (asterisks) from one another. $\mathbf{f}$ At the apical tip of the testioles, a few new germ cell rosettes surrounding a central polyfusome (triangles) can still be seen. Abbreviations: a and b, apical and basal sides of testis, respectively; $\mathrm{c}$, somatic cells forming the apical cap; ips, inner peritoneal sheath; ps, peritoneal sheath; t, testiolar tubule. 
a

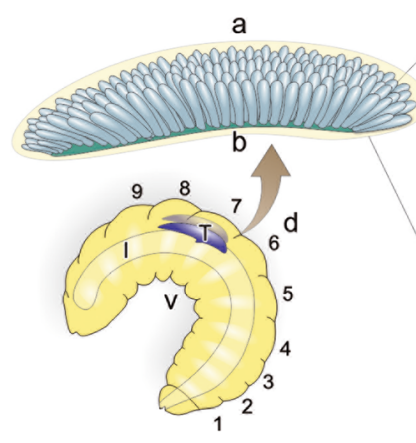

b

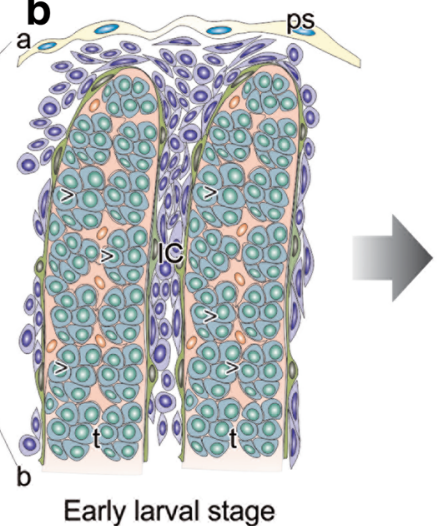

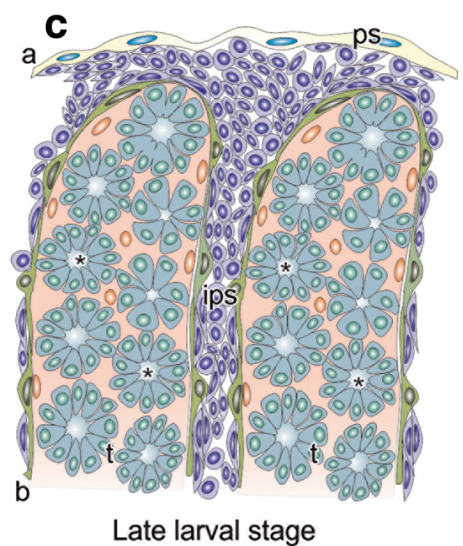

Figure 6. Schematic representation of testis development in drone larvae. a Location and general structure of the testes. b Inner architecture of the testiolar tubules for the early larval stages (L2-L4), and $\mathbf{c}$ for the feeding phase of the fifth instar (L5F). In the latter, the spermatogonial clusters have already acquired the germ cell rosette architecture, where the nuclei are in a peripheral position surrounding a central polyfusome resulting from incomplete cytokinesis. Body segments are numbered. Arrowheads indicate germ cell clusters in $\mathbf{b}$, and asterisks mark the polyfusomes of such clusters in c. Abbreviations: a, apical; b, basal; d, dorsal, v, ventral; I, intestine; IC, interstitial cells; ps, peritoneal sheath; $\mathrm{T}$, testis; t, testiolar tubule.

presented by Hoage and Kessel (1968) show that the germ cells in these clusters are now primary spermatocytes (meiotic prophase I). This is when 12-16 primary spermatocytes can be distinguished in the cross sections (Figure $7 \mathrm{~b}, \mathrm{c}$ ). In the later spinning phases (L5S2 and L5S3), the central polyfusomes at the basal end of the testiolar tubules are dissolved and the germ cells are now randomly distributed inside the clusters (Figure 7d-f). The germ cells are now likely secondary spermatocytes.

An interesting phenomenon is apparent in the apical region of some testioles, where nuclear condensation and organelle degradation indicate a sweep of cell death that seems to have affected several germ cell clusters (Figure 7e). Also, there is a developmental gradient in spermatogenesis progression along the apical to basal axis of the testiolar tubules. Hence, it is possible that the younger, more apically located germ cell clusters may have lost the correct timing for entering meiosis and, blocked from further development, entered a cell death program.

The following micrographs were taken from testes of early prepupae (PP1). They present an overview of testiolar tubules in a basal position (Figure $8 \mathrm{a}$ ) and a higher resolution image of a cross section through a testiolar tubule (Figure $8 b$ ), both showing clusters of early secondary spermatocytes. The basal-most portion of the testiolar tubules that connects to the proximal vas deferens has become a slender basal stalk that does not contain germ cells. Clear vesicles can be seen in the cytoplasm of these early secondary spermatocytes, which, within each cluster, still appear connected to one another via intercellular bridges (Figure $8 b$ ).

\subsection{Testis architecture in the pupal and pharate-adult developmental stages}

Shortly after the pupal molt, the secondary spermatocytes have lost their nuclear membrane. The darkly staining chromatin is seen highly condensed and surrounded by a clear cyto/ nucleoplasm (Figure 8c). Laminar threads that run across the cyto/nucleoplasm likely represent the endoplasmatic reticulum-derived laminar membranes seen in the electron microscopy images of dividing secondary spermatocyte nuclei (Hoage and Kessel 1968). A few metaphase plates of the second meiotic division can still be seen in Figure 8d. 


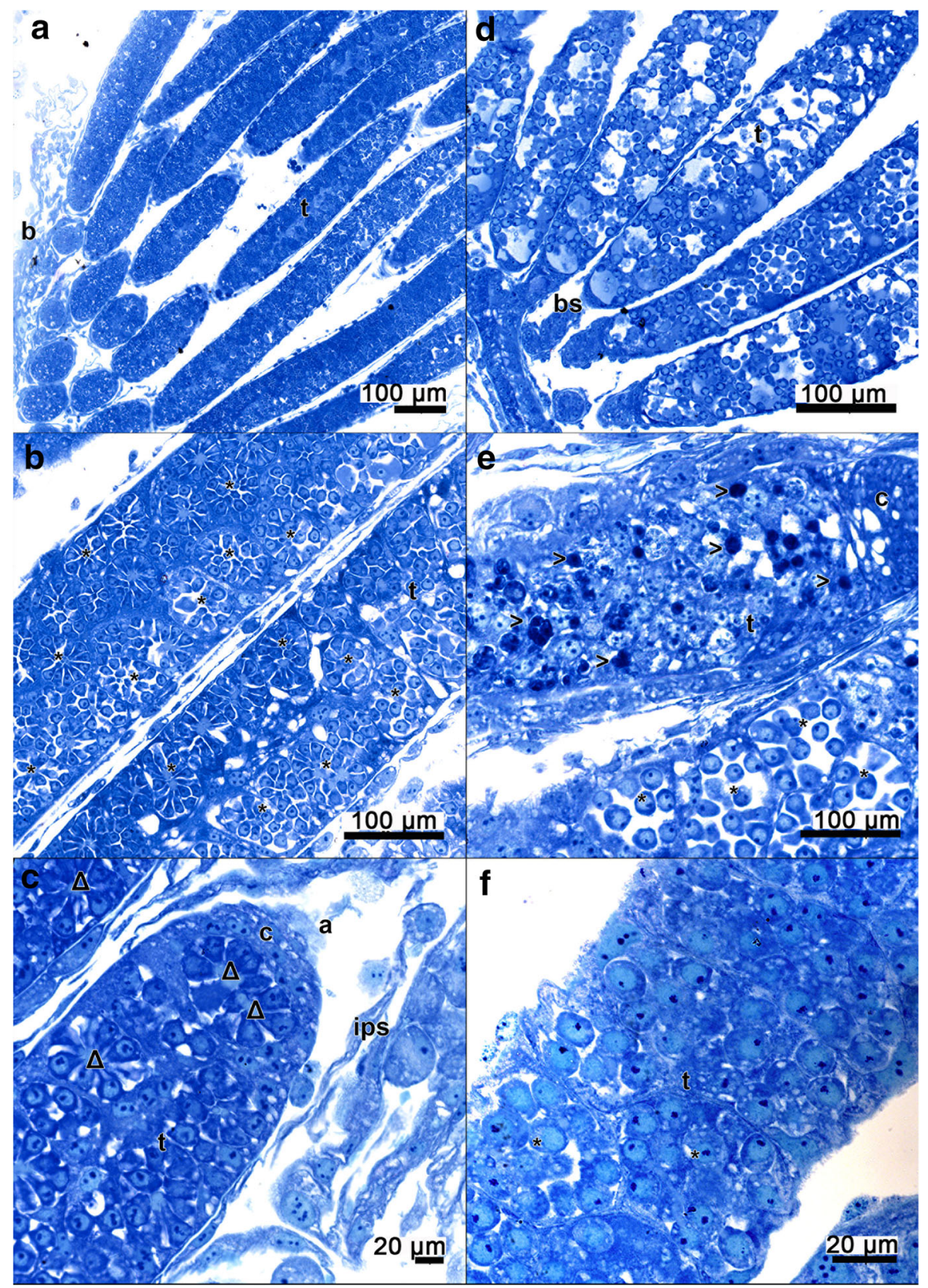

Figure 7. Testis development and first meiotic division in the fifth instar spinning-phase larva. a-c Early fifth instar spinning phase (L5S1). $\mathbf{d}$ and e Mid spinning phase (L5S2). f Terminal spinning-phase (L5S3) testes. a Overview of longitudinally sectioned testiolar tubules. $\mathbf{b}$ Section in the mid region of testioles showing clusters of primary spermatocytes (asterisks), and $\mathbf{c}$ in the apical region, showing spermatogonial clusters that are apparently preparing to enter meiosis (triangles). d Section in the basal region of the testis, showing the basal stalks that connect the testioles with the proximal vas deferens. Some of the clusters appear to have lost structure in this region of the testiolar tubules. e Nuclear condensation and disintegration of cellular organelles (arrowheads) indicate massive cell death in primary spermatocyte clusters right beneath the apical cap. $\mathbf{f}$ In the late spinning stage (L5S3), the rosette-like architecture of the germ cell clusters has become dissolved, and the spermatocytes are now evenly distributed within the clusters. Abbreviations: $a$, apical and $b$, basal side of testis; bs, basal stalk of testiole; c: apical cap; ips, inner peritoneal sheath; t, testiolar tubule. 

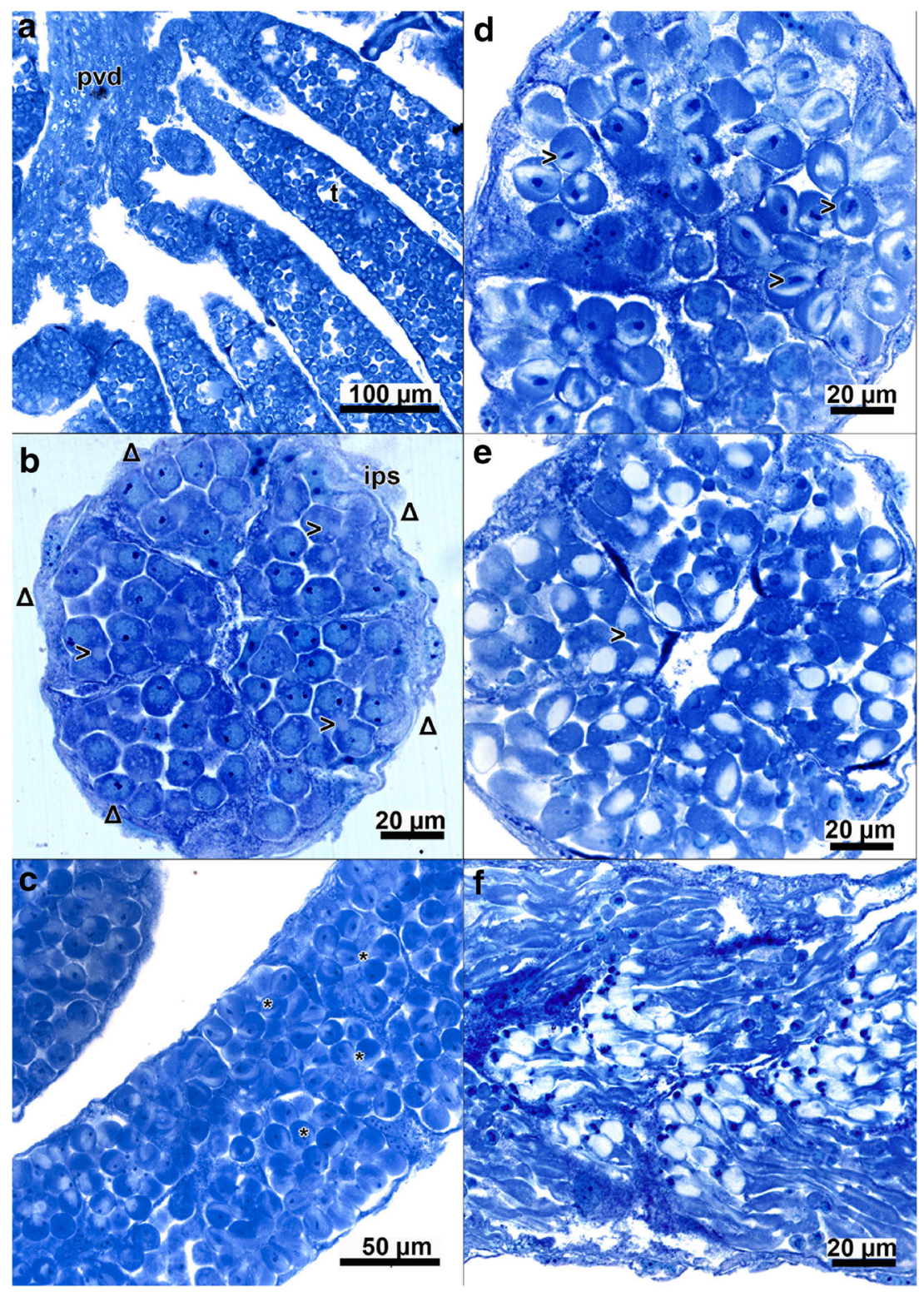

Figure 8. Conclusion of the meiotic divisions and onset of spermiogenesis in prepupae $(\mathbf{a}, \mathbf{b})$ and pupae $(\mathbf{c}-\mathbf{f})$. a General architecture in the basal testiolar region of the early prepupal stage (PP1), showing the basal stalks and basal spermatocyte clusters. b Cross section of a testiole showing five germ cell clusters; the secondary spermatocytes are still connected to each other via intercellular bridges (arrowheads). Triangles outside this section mark the position of these five germ cell clusters. $\mathbf{c}$ and $\mathbf{d}$ Sections of early pupal testioles showing secondary spermatocytes (asterisks) at the beginning (c) and in progression to the metaphase of the second meiotic division, indicated by the presence of a metaphase plate (arrowhead) (d). The nuclear membrane has been dissolved, and chromatin (arrowheads) is now contained within a spindle shaped, clear cyto/nucleoplasm containing longitudinal lamellae. e Cross section of a testiole from a dark-eyed pupae (Pd) showing six clusters filled with spermatids. The spherical nucleus is adjacent to a clear vesicle, and a flagellum begins to be formed (arrowhead). $\mathbf{f}$ Longitudinal section of a late pupal stage (Pd) testiolar tubule in a more basal position, showing early spermiogenesis stages. All spermatozoa in these clusters have the same longitudinal orientation, with a darkly stained apical end and a growing flagellum at the posterior end. Abbreviations: ips, inner peritoneal sheath; pvd, proximal vas deferens; $t$, testiolar tubule. 


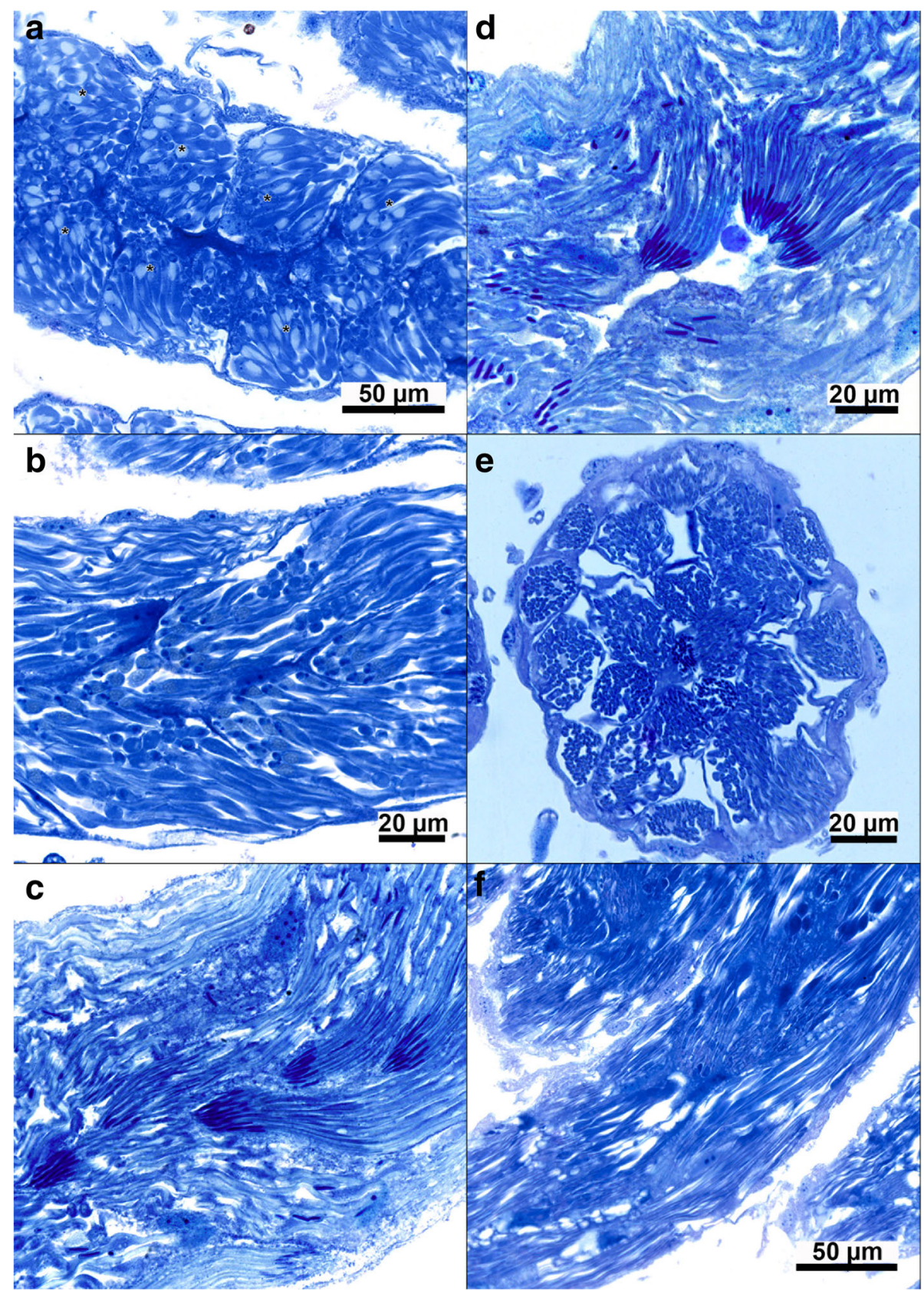

Figure 9. Spermiogenesis in pharate-adult drones. $\mathbf{a}$ and $\mathbf{b}$ Testioles of early pharate adults (Pdl stage) showing the progression of spermiogenesis along the longitudinal axis of a testiole. a Apical region with early (asterisks). b Basal region with late spermiogenesis stages. In both images, groups of small blebs can be seen in close association with spermatozoa, indicating blebs of cytoplasm that were extruded from spermatids during spermiogenesis. In mid pharate-adult (Pdm) stages (c, d ), the chromatin in sperm nuclei is condensed, and spermatozoa continue aligned and forming bundles. e and $\mathbf{f}$ In late pharate-adult (Pdd) testiolar tubules, the germ cell cysts gradually disintegrate and the spermatozoa become individualized. 

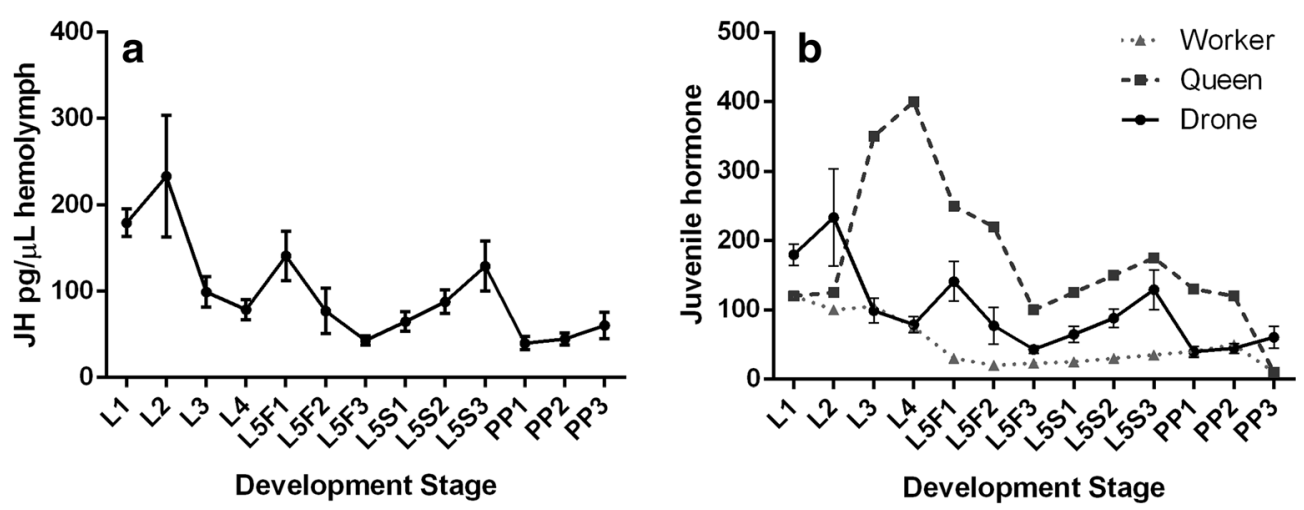

Figure 10. Juvenile hormone $(\mathrm{JH})$ levels in the hemolymph of honey bee larvae. a JH levels in drone larvae measured by radioimmunoassay. Each data point represents the mean \pm SEM of five biological samples. b Projection of the JH levels found in drone larvae against those of queens and workers; the titer curves for queens and workers are redrawn from Hartfelder and Engels (1998). Note that the quantification methods used in the JH analyses for queens and workers (Rembold 1987; Rachinsky et al. 1990) differed from the one used in the current study. Hence, the comparison of drone JH levels with those of the female castes represents relative and not absolute values. Nonetheless, the JH levels of drones are generally intermediate between queens and workers.

With the completion of this division, the germ cell cysts are now composed of spermatids entering spermiogenesis (Figure 8e). The spherical nuclei are closely apposed to a clear vesicle that likely represents residual material from the cyto/ nucleoplasm seen in Figure 8c, and the extension at the opposite end indicates the beginning of flagellum formation. This section (Figure 8e) is a cross section in a relatively apical position of a testiolar tubule of a Pd-stage pupa. The next image (Figure 8f) was taken from a more basal section of a testiolar tubule in the same developmental stage, representing a more advanced spermiogenesis stage. It shows a darkly staining acrosomal vesicle and the elongating tails of the spermatozoa that are still connected and aligned to each other in the clusters.

The onset of pupal apolysis in the P3 (Pd) phase (Elias-Neto et al. 2009) defines all subsequent phases up to the adult ecdysis as the pharate-adult stage of development. The testiolar tubule structure and progressing spermiogenesis in early pharate adults (Pdl) are depicted in longitudinal sections through the apical (Figure 9a) and basal region of a testiolar tubule (Figure 9b), respectively. The images clearly show the developmental gradient along the apical to basal axis of the testiolar tubules. The elongating spermatozoa

\footnotetext{
testis formation germ cell cluster formation / spermatogonia

meiosis II / secondary spermatocytes

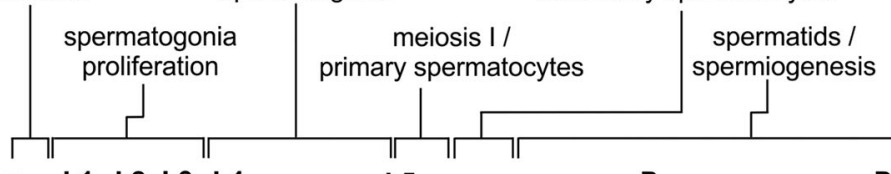

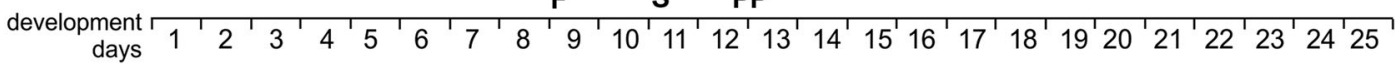

Figure 11. Timeline of testis development and spermatogenesis in honey bee drones reconstructed from histological sections. The sequence of major events in gonad development is shown in relation to the preimaginal stages and their approximate duration in days (Stabe 1930; Human et al. 2013). The timing with respect to meiosis stages is based on our histological data, as well as the detailed ultrastructure images of Hoage and Kessel (1968).
} 
form longitudinal bundles within the germ cell cysts. Besides these large spermatozoa, groups of smaller blebs are seen within the clusters. These could be either small spermatids that possibly did not enter spermiogenesis and will degenerate, or blebs of cytoplasm that has been eliminated from the spermatids during spermiogenesis.

In mid pharate adults (Pdm; Figure 9c, d), the bundled spermatozoa have highly condensed and darkly stained nuclei. The cytoplasmatic blebs mentioned above are still visible, but appear clearly separated from the sperm bundles. In late pharate adults (Pdd), shortly before adult ecdysis, the sperm bundles are more condensed, with vast empty spaces within and between the clusters (Figure 9e), and in the more basal region of the testiolar tubules, the spermatozoa clusters are already dissolving and the spermatozoa are now individualized (Figure 9f).

\subsection{Juvenile hormone levels in drone larvae}

We report here a detailed series of measurements on the $\mathrm{JH}$ levels present in hemolymph of the larval stages of honey bee drones (Figure 10a). We ended these measurements with the late prepupal stage, because during the pupal and most of the pharate-adult phases, the $\mathrm{JH}$ titer remains at basal levels in honey bee queens and workers (Rembold 1987; Hartfelder and Engels 1998), as is the case in all holometabolous insects (Belles 2020). The JH levels differ significantly during larval development (one-way ANOVA $\mathrm{F}_{(12}$, 52 ) $3.435 ; p=0.0009$ ). In particular, all the stages following the L5F3 stage have significantly lower JH hemolymph titers than the L1/L2 stage (Tukey's multiple comparisons, $p<0.05$ ). As shown in Figure 10b, from the L3 stage onwards, the $\mathrm{JH}$ titer levels of drone larvae lie right between those of queens and workers. The temporal profile of the drone $\mathrm{JH}$ levels is aligned with that of the female castes, except for the very early fifth instar (L5F1), when drones show a small, intermittent $\mathrm{JH}$ peak that is not found in females.

\section{DISCUSSION}

In this descriptive study of gonad and germ cell development in honey bee drones, we present a comprehensive overview based on histological sections. The intention was to provide fundamental background information for future studies, especially those directed towards comparative genomics and gene expression analysis in the reproductive system of honey bees and bees in general. In Figure 2, we present an overall view on the dynamics of testis development. With all images taken at the same magnification, these reveal the strong increase in testis size between the fourth larval instar and the onset of the spinning phase in the fifth instar. In Figure 11, we present a general overview of the developmental events in the gonad of drones. In this figure, we include the embryonic stage for completeness, although in our histological study, we did not address this stage.

The embryonic stage deserves further attention, because once a male of female honey bee larva hatches from the egg, its gonad architecture is already defined in general terms, and all the ovariolar/testiolar tubule primordia are visible as clearly separated units (Zander 1916; Hartfelder et al. 2018; this study). The importance of the embryonic stage for understanding gonad development is also evident in the context of honey bee sex determination (reviewed in Gempe et al. 2009; Biewer et al. 2015) and the recent study by Roth et al. (2019), who showed that the feminizer gene, a key factor in the embryonic sex determination cascade of A. mellifera, is also crucial for the expression of caste-specific plasticity in the ovary phenotype in response to the larval feeding program.

Nonetheless, the only detailed study on the embryonic gonad also dates back to the early twentieth century, with the still outstanding work of James Allen Nelson (1915). In drawings from transverse sections of 54-68-h old of embryos, he shows that the somatic gonad is derived from what he calls a genital ridge in the outer layer of the visceral wall mesoderm. The origin of the germline cells also needs further work, as in the honey bee embryo, there is no evidence for the presence of pole cells (Nelson 1915; DuPraw 1967) like in Drosophila, and the current view is that they are determined by cell-cell interactions and epigenetic mechanisms (Cridge et al. 2017). 


\subsection{Postembryonic development of the testis, formation of germ cell clusters, and spermiogenesis}

Postembryonic testis development can essentially be divided into three stages. In the first one, comprising the first to the early fifth instar, the testiolar tubules grow in length by mitotic division of germline and somatic cells. During the remainder of the fifth larval instar and in early pupae, meiosis takes place, before spermiogenesis then dominates the picture in the testes of pharate-adult drones.

In the early larval stages (L1-L3), the histological architecture of the larval testis is highly similar to that of the larval ovary (reviewed in Hartfelder et al. 2018), with dozens of testiolar tubules aligned in parallel along the apical-basal axis of the testis. Yet already in the L4 stage, the testiolar tubules are longer than the larval ovarioles, which, at that stage are only 5-8 cell layers in length (Hartfelder and Steinbrück 1997), compared with the dozens of cell layers in the testiolar tubules (Figure $4 a, b$ ).

The expansion in testiolar length by mitotic divisions along the apical-basal axis (Figure 5) is particularly pronounced in the early fifth instar (L5F1-L5F3). Also in queen and worker ovaries, intense mitotic activity was found in these stages (Schmidt Capella and Hartfelder 1998). A further similarity with the ovarioles is in the apical tip of the testiolar tubules, where a clearly distinct apical cap structure composed of somatic cells is present. This apical cap is easily visible in freshly dissected testes of late fifth instar larvae (Figure 2f).

Despite these overall similarities with the larval honey bee ovary, the male germ cell compartment appears to be less organized (Figure 5), as in the ovarioles of this stage, well-defined germ cell clusters are already organized around a central polyfusome (Hartfelder and Steinbrück 1997; Schmidt Capella and Hartfelder 2002). It is only in spinning-stage drone larvae that the germ cell clusters become physically separated from each other by an envelope of somatic cells (Figure 7). The central polyfusomes then apparently become dissolved (Figure 7d, e) as the spermatogonia enter meiosis, when the larvae prepare for metamorphosis (Figure 11). Hence, the polyfusome seems to be of only transient importance in the testiolar tubules of drones. In contrast, it is a lifetime elementary structure in the ovarioles of honey bee females (Hartfelder and Steinbrück 1997; Schmidt Capella and Hartfelder 2002; Tanaka and Hartfelder 2004), just as in all other insect species with a polytrophic meroistic ovary type (Büning 1994; Roth and Lynch 2009).

In the pupal stages, the testiolar tubules show a marked apical-to-basal gradient in the progression of spermiogenesis, and while spermatids are still present at the apical end, spermiogenesis is already well under way in the basal part of the testioles. In the pharate-adult stages, spermiogenesis then gradually comes to an end (Figure 9), and the somatic cover around the germ cell clusters that maintained the developing spermatozoa together as sister-cell groups becomes dissolved. The spermatozoa are now individualized.

\subsection{Meiosis}

Meiosis in the haploid germline of Hymenoptera males has long attracted attention (Meves 1907; Nachtsheim 1913). Two peculiarities are worthy of note. The first is the abortive nature of the first meiotic division, which conserves the full chromosomal complement in a single secondary spermatocyte. Nonetheless, as the centrioles of the primary spermatocyte had undergone apparently several rounds of duplication, these need to be eliminated to avoid chromosomal loss. This process of centriole elimination was clearly evidenced in the electron micrographs of Hoage and Kessel (1968), who noted numerous centriole-containing cytoplasmatic blebs that appeared to be cleaved off the plasma membrane of primary spermatocytes. Such blebs were already noted by Meves (1907) and later described by Sharma et al. (1961) and Cruz-Landim and Beig (1980) in A. mellifera and the stingless bee Scaptotrigona postica, respectively. The second peculiarity is that the two spermatids formed in the second meiotic division are of different size, and it is still a question of debate whether both spermatids will give rise to spermatozoa in bees (Kerr and da Silveira 1974), or if only the larger one undergoes spermiogenesis, while the smaller 
one degenerates (Cruz-Landim and Silva de Moraes 1980).

\subsection{Germline stem cell maintenance}

A critical issue for high reproductive rates is the maintenance of germline and somatic stem cell activity in the gonads, and this question is particularly well studied in the Drosophila melanogaster ovary (Gilboa 2015) and testis (Tamirisa et al. 2018). In contrast, in the honey bee ovary, the position of germline and somatic stem cells in the very much elongated germarium, respectively terminal filament, is still an open question (Tanaka and Hartfelder 2004), but like in the Drosophila ovary, Notch signaling has been shown to be a critical factor for oogenesis progression in the honey bee ovarioles (Duncan et al. 2016). Even less is known concerning stem cell activity in the drone testis, and thought goes that until entry into meiosis, germline stem cells are anchored around an apical cell located at the top of each testiolar tubule (Cruz Landim 2009). In Figure 4d, which shows the apical end of testiolar tubules, it is possible to see a cap-like structure that could function as a stem cell niche, but we could not identify a central apical cell like that shown by Cruz Landim (2009), so the apical cell/stem-cell niche question also deserves further attention, especially through the use of molecular markers.

\subsection{Hormonal regulation of testis development and spermatogenesis}

Two hormonal systems are key regulators of insect reproduction, juvenile hormones, and ecdysteroids (for recent reviews, see Santos et al. 2019; Swevers 2019). However, as most studies have their focus on female reproduction in the adult life cycle, males are the neglected gender. In fact, most of the studies on the role of hormones in male reproduction are concerned with their effects on the function of male accessory glands in adult males, including honey bees (Colonello and Hartfelder 2003; Harano 2013). In contrast, testis development and spermatogenesis in honey bees are fully integrated within the progression of postembryonic development.
A time course of the ecdysteroid titer in honey bee drones has been published for the pupal and pharate-adult stages (de Oliveira Tozetto et al. 2007). In essence, the ecdysteroid titer profile of drone pupae is similar to that of the female castes (Pinto et al. 2002) especially so with the queen profile. It is marked by very high ecdysteroid levels during the early pupal stages, with a peak in the pink-eyed stage, followed by a gradual decline during pharate-adult development. Data on the larval ecdysteroid titer for honey bee drones have also been obtained (Tozetto 1997) in a Doctoral study, but have not yet been published.

Due to its key role in caste development, juvenile hormone $(\mathrm{JH})$ has drawn much more attention than ecdysteroids. The levels of JH-III, which is the sole JH moiety present in Hymenoptera, have been measured by physicochemical (Rembold 1987) and radioimmunoassay methods (Rachinsky et al. 1990) for queens and workers, but no such data were available so far for drones. Here we present this data for the entire period of larval development in drones. We did not include the pupal and pharate-adult stages, as in these, the $\mathrm{JH}$ titer in the female castes remains at basal levels (Rembold 1987; Hartfelder and Engels 1998). As shown in Figure 10b, the JH titer values for drone larvae lie right between those of queens and workers, except for the very early instars (L1 and L2) and the early fifth instar (L5F1), when drones show a small, intermittent $\mathrm{JH}$ peak that is not found in the female castes.

With respect to the relationship between hormone titers and testis development, the small JH titer peak in the L5F1 phase coincides with the appearance of well-separated spermatogonial clusters in the testiolar tubules (Figure 4c, d; Figure 11). The subsequent gradual increase in the $\mathrm{JH}$ titer, which is associated with the larval/pupal transition in Holometabola (Belles 2020), accompanies the gradual entry of the spermatogonia into the first (abortive) meiotic division (Figures 6, 7, and 11). During the early prepupal stage (Figure 8a, b), in the presence of low $\mathrm{JH}$ titers, this first division terminates and the secondary spermatocytes prepare for the second division. After the pupal molt, in 
the presence of high ecdysteroid levels (de Oliveira Tozetto et al. 2007), the secondary spermatocytes complete the second meiotic division and become spermatids (Figure 8ce; Figure 11). The transformation of spermatids into spermatozoa then occurs in the presence of declining ecdysteroid hemolymph titers in pharate-adult development (Figures 9 and 11). Evidently, we discuss here a temporal correlation between the variation in morphogenetic hormone levels and spermatogenesis events, but without experimental evidence, it is not yet possible to affirm a causal role for these hormones in testis development and spermatogenesis.

\subsection{Conclusion}

We present here a histological atlas that illustrates for the first time the entire timeline of testis development and spermatogenesis in honey bee drones, covering all the stages of larval, pupal, and pharate-adult development. The first schematic figure (Figure 6) summarizes the main histological information for the larval stages. During these, spermatogonia gradually become organized into clusters, held together by a central polyfusome and separated from other clusters by a layer of somatic cells. Male and female honey bee larvae, thus, share essential architectural characteristics during early larval development. But the two sexes then differ from each other with the entry into metamorphosis. As illustrated in Figure 11, the spermatogonia now all enter meiosis and soon conclude the first (abortive) meiotic division. Soon after the pupal molt, the second meiotic division takes place, and the spermatids then undergo and complete spermiogenesis in the pharate-adult stage. We complemented this histological atlas on testis development and spermatogenesis with an analysis of the $\mathrm{JH}$ levels in the hemolymph of drone larvae, which, to our knowledge, is the first data for this crucial insect hormone in the development of the male sex of the honey bee. The detailed description of the timeline of testis development and its endocrine underpinnings in honey bees will certainly be of relevance to the planning of comparative genomics and transcriptomics studies directed towards the understanding of the transgressive gonad size in the genus Apis. Furthermore, we hope that this study will also stimulate similar research in other social Hymenoptera, so that their males are no longer the neglected sex.

\section{ACKNOWLEDGMENTS}

We thank Luiz Roberto Aguiar for his help in obtaining drone larvae from Apis mellifera hives kept in the apiary of the Genetics Department on our campus. Vani Maria Alves helped us with the embedding and sectioning of the histological blocks, and Roberta Ribeiro Costa Rosales and Tiago DePintor provided assistance in the image acquisition from histological sections and freshly prepared testis whole mounts. We also thank the anonymous reviewers for their helpful comments on the original version of this manuscript.

\section{AUTHOR CONTRIBUTIONS}

MMGB and KH conceived the study; DCL, RPD, and JRM prepared the histological sections; DCL and $\mathrm{KH}$ performed the $\mathrm{JH}$ titer analysis. DES participated in the interpretation of structures and elaborated artwork. KH wrote the manuscript draft, which was revised and had its final version approved by all coauthors.Funding information

This study received financial support from the Sao Paulo Research Foundation (FAPESP, grants 2009/15772-3, 2016/16622-9, 2017/09128-0).

\section{COMPLIANCE WITH ETHICAL STANDARDS}

Conflict of interest The authors declare that they have no conflict of interest.

Développement testiculaire et spermatogenèse chez les mâles de l'abeille, Apis mellifera $\mathbf{L}$.

abeille domestique / mâle / développement des testicules / cellules germinales / spermatogenèse. 
Hodenentwicklung und Spermatogenese bei Drohnen der Honigbiene Apis mellifera $\mathbf{L}$.

\author{
Honigbiene / Drohne / Hodenentwicklung / Keimzellen / \\ Spermatogenese.
}

\section{REFERENCES}

Adams, J., Rothman, E.D., Kerr, W.E., Paulino, Z.L. (1977) Estimates of number of sex alleles and queen matings from diploid male frequencies in a population of Apis mellifera. Genetics 86, 583-596.

Baer, B. (2005) Sexual selection in bees. Apidologie 36, 187-200.

Belles, X. (2020) Insect metamorphosis. Academic Press, Cambridge.

Biewer, M., Schlesinger, F., Hasselmann, M. (2015) The evolutionary dynamics of major regulators for sexual development among Hymenoptera species. Front. Genet. 6, 124.

Bishop G.H. (1920) Fertilization in the honeybee. I. The male sexual organs: their histological structure and physiological functioning. J. Exp. Zool. 31, 225-265.

Boomsma, J.J., Ratnieks F.L.W. (1996) Paternity in eusocial Hymenoptera. Philos. Trans. R. Soc. B Biol. Sci. 351, 947-975.

Boomsma, J.J., Baer, B., Heinze, J. (2005) The evolution of male traits in social insects. Annu. Rev. Entomol. 50, 395-420.

Büning, J. (1994) The Insect Ovary. Chapman \& Hall, London.

Colonello N.A., Hartfelder K. (2003) Protein content and pattern during mucus gland maturation and its ecdysteroid control in honey bee drones. Apidologie 34, 257-267.

Cridge, A.G., Lovegrove, M.R., Skelly, J.G., Taylor, S.E., Petersen, G.E.L., Cameron, R.C., Dearden, P.K. (2017) The honeybee as a model insect for developmental genetics. Genesis 55, e23019.

Cruz Landim, C., 2009. Abelhas: Morfologia e Função de Sistemas. Editora Unesp, São Paulo.

Cruz-Höfling, M.A., Cruz-Landim, C., Kitajima, E.W. (1970) The fine structure of spermatozoa from the honeybee. Anais Acad. Bras. Ciênc. 42, 69-78.

Cruz-Landim, C., Beig, D., (1980) An electron microscopic study of spermatogenesis in the drone of Scaptotrigona postica (Hymenoptera, Apidae). Int. J. Invert. Reprod. 2, 271-283.

Cruz-Landim, C., Silva de Moraes, R.L.M. (1980) Observations on the the mitochondrial complex and head differentiation during spermatogenesis in the stingless bee Malipona quadrifasciata anthidioides Lep.. Cytobios 27, 167-175. de Oliveira Tozetto, S, Engels W (2013) Classification of substages in preimaginal development of honey bee drones (Hymenoptera: Apidae). Entomol. Gen. 3, 287293.

de Oliveira Tozetto, S., Bitondi, M.M.G., Dalacqua, R., Simões, Z.L.P. (2007) Protein profiles of testes, seminal vesicles and accessory glands of honey bee pupae and their relation to the ecdysteroid titer. Apidologie 31, 1-12.

Duncan, E.J., Hyink, O., Dearden, P.K. (2016) Notch signalling mediates reproductive constraint in the adult worker honeybee. Nat. Commun. 7, 12427.

DuPraw, E.J. (1967) The honey bee embryo. In: Wilt, H.R., Wessels, N.K. (eds.) Methods in Developmental Biology. pp. 183-217. Thomas J. Corwell, New York.

Elias-Neto, M., Soares, M.P.M., Bitondi, M.M.G. (2009) Changes in integument structure during the imaginal molt of the honeybee. Apidologie 40, 29-39

Ferreira A, Abdalla FC, Kerr WE, Cruz-Landim C (2004) Comparative anatomy of the male reproductive internal organs of 51 species of bees. Neotrop. Entomol. 33:569-576.

Garófalo, C.A. (1980) Reproductive aspects and evolution of social behavior in bees (Hymenoptera, Apoidea). Rev. Bras. Genet. 3, 139-152.

Gempe, T., Hasselmann, M., Schiøtt, M., Hause, G., Otte, M., Beye, M. (2009) Sex determination in honeybees: two separate mechanisms induce and maintain the female pathway. PLoS Biol. 7, e1000222.

Gilboa, L. (2015) Organizing stem cell units in the Drosophila ovary. Curr. Opin Genet. Dev. 32, 31-36.

Green II, D.A., Extavour, C.G. (2012) Convergent evolution of a reproductive trait through distinct developmental mechanisms in Drosophila. Dev. Biol. 372, $120-130$.

Harano, K, (2013) Effects of juvenile hormone analog on physiological and behavioral maturation in honeybee drones. Apidologie 44, 586-599.

Hartfelder, K., Engels, W. (1998) Social insect polymorphism: hormonal regulation of plasticity in development and reproduction in the honeybee. Curr. Top. Dev. Biol. 40, 45-77.

Hartfelder, K., Steinbrück, G. (1997) Germ cell cluster formation and cell death are alternatives in castespecific differentiation of the larval honey bee ovary. Invertebr. Reprod. Dev. 31, 237-250.

Hartfelder, K., Bitondi, M.M.G., Brent, C., GuidugliLazzarini, K.R., Simões, Z.L.P., Stabentheiner A., Tanaka E.D., Wang, Y. (2013) Standard methods for physiology and biochemistry research in Apis mellifera. J. Apic. Res. 52(1) doi: https://doi. org/10.3896/IBRA.1.52.1.06.

Hartfelder, K., Tibério G.J., Lago, D.C., Dallacqua, R.P., Bitondi, M.M.G. (2018) The ovary and its genes developmental processes underlying the establishment and function of a highly divergent reproductive system in the female castes of the honey bee, Apis mellifera. Apidologie 49, 49-70. 
Hoage, T.R., Kessel, R.G. (1968) An electron microscope study of the process of differentiation during spermatogenesis in the drone honey bee (Apis mellifera L.) with special reference to centriole replication and elimination. J. Ultrastruct. Res. 24, 6-32.

Human H, Brodschneider R, Dietemann V, Dively G, Ellis JD, Forsgren E, Fries I, Hatjina F, Hu F-L, Jaffé R, Briin Jensen A, Köhler A, Magyar JP, Özkyrym A, Pirk CWW, Rose R, Strauss U, Tanner G, Tarpy DR, van der Steen JJM, Vaudo A, Vejsnæs F, Wilde J, Williams GR, Zheng H-Q (2013) Miscellaneous standard methods for Apis mellifera research. J. Apic. Res. 52(4) doi: https://doi.org/10.3896/IBRA.1.52.10.

Kerr, W.E., da Silveira Z.V. (1974) A note on the formation of honeybee spermatozoa. J. Apic. Res. 13, 121-126.

Koeniger, G. (2005) The neglected gender - males in bees. Apidologie 36, 143-144.

Koeniger, G., Koeniger, N., Tingek, S., Phiancharoen, M. (2005) Variance in spermatozoa number among Apis dorsata drones and among Apis mellifera drones. Apidologie 36, 279-284.

Koeniger, G., Koeniger, N., Ellis, J., Connor, L. (2014a) Mating biology of honey bees (Apis mellifera). Wicwas Press, Kalamazoo.

Koeniger, G., Koeniger, N., Tiesler, F.-K. (2014b) Paarungsbiologie und Paarungskontrolle bei der Honigbiene. Buschhausen Verlag, Herten.

Kraus, F.B., Neumann, P., Moritz, R.F.A. (2005) Genetic variance of mating frequency in the honeybee (Apis mellifera L.). Insectes Soc. 52, 1-5.

Kronauer, D.J.C., Schoning, C., Pedersen, J.S., Boomsma, J.J., Gadau, J. (2004) Extreme mating frequency and colony fission in African army ants. Mol. Ecol. 13, 2381023-88.

Lensky, Y., Ben-David, E., Schindler, H. (1979) Ultrastructure of spermatozoa of the mature drone honeybee. J. Apic. Res. 18, 264-271.

Lino-Neto, J., Bão, S.N., Dolder, H. (2000) Sperm ultrastructure of the honey bee (Apis mellifera L.) (Hymenoptera, Apidae) with emphasis on the nucleusflagellum transition region. Tissue Cell 32, 322-327.

Louveaux J. (1977) Anatomie de l'abeille: X - L'appareil reproducteur du male, Bull. Tech. Apic. 4, 43-48.

Meves, F. (1907) Die Spermatocytenteilungen bei der Honigbiene (Apis mellifica L.) nebst Bemerkungen über Chromatinreduktion. Arch. Mikroskop. Anat. 70, 414-491.

Nachtsheim, H. (1913) Cytologische Studien über die Geschlechtsbestimmung bei der Honigbiene (Apis mellifica L.). Arch. Zellforsch. 11, 169-241.

Nelson, J.A. (1915) The Embryology of the honey bee. Princeton University Press, Princeton, 304 pp.

Nelson, J.A. (1924) Morphology of the honey bee larva. J. Agric. Res. 28, 1167-1213.

Pinto, L.Z., Hartfelder, K., Bitondi, M.M.G., Simões, Z.L.P. (2002) Ecdysteroid titers in pupae of highly social bees relate to distinct modes of caste development. J. Insect Physiol. 48, 783-790.
Rachinsky, A., Strambi, C., Strambi, A., Hartfelder, K. (1990) Caste and metamorphosis - hemolymph titers of juvenile hormone and ecdysteroids in last instar honeybee larvae. Gen. Comp. Endocrinol. 79, 31-38.

Rembold, H. (1987) Caste specific modulation of juvenile hormone titers in Apis mellifera. Insect Biochem. 17, 1003-1006.

Rembold, H., Kremer, J.-P., Ulrich, G.M. (1980) Characterization of the postembryonic developmental stages of the female castes of the honey bee, Apis mellifera L. Apidologie 11, 29-38.

Roth, S., Lynch, J.A. (2009) Symmetry breaking during Drosophila oogenesis. Cold Spring Harb. Perspect. Biol. 1, a001891.

Roth, A., Vleurinck, C., Netschitailo, O., Bauer, V., Otte, M., Kaftanoglu, O., Page, R.E., Beye, M. (2019) A genetic switch for worker nutrition-mediated traits in honey bees. PLoS Biology 17:e3000171.

Santos, C.G., Humannm F.C., Hartfelder, K. (2019) Juvenile hormone signaling in insect oogenesis. Curr. Opin. Insect Sci. 31, 43-48.

Schlüns, H., Schlüns, E.A., van Praagh, J., Moritz, R.F.A. (2003) Sperm numbers in drone honeybees (Apis mellifera) depending on body size. Apidologie 34, 577-584.

Schmidt Capella, I.C., Hartfelder, K. (1998) Juvenile hormone effect on DNA synthesis and apoptosis in castespecific differentiation of the larval honey bee (Apis mellifera L.) ovary. J. Insect Physiol. 44, 385-391.

Schmidt Capella, I.C., Hartfelder, K. (2002) Juvenilehormone-dependent interaction of actin and spectrin is crucial for polymorphic differentiation of the larval honey bee ovary. Cell Tissue Res. 307, 265-272.

Sharma, G.P., Gupta, B.L., Kumbkarni, C.G. (1961) Cytology of spermatogenesis in the honeybee, Apis indica (F.). J. R. Micros. Soc. 79, 337-351.

Snodgrass, R.E. (1956) Anatomy of the Honey Bee. Cornell University Press, Ithaca, 334 pp.

Stabe, H.A. (1930) The rate of growth of worker, drone and queen larvae of the honeybee, Apis mellifera Linn.. J. Econ. Entomol. 23, 447-453.

Stürup, M., Baer-Imhof, D.R., Nash, J.J., Boomsma, J.J., Baer, B. (2013) When every sperm counts: Factors affecting male fertility in the honeybee, Apis mellifera . Behav. Ecol. 24, 1192-1198.

Swevers, L. (2019) An update on ecdysone signaling. Curr. Opin. Insect Sci. 31, 8-13.

Tamirisa S., Papagiannouli, F., Rempel, E., Ermakova, O., Trost, N., Zhou, J., Mundorf, J., Brunel, S., Ruhland N., Boutros M., Lohmann, J.U., Lohmann, I. (2018) Decoding the regulatory logic of the Drosophila male stem cell system. Cell Rep. 24, 3072-3086.

Tanaka, E.D., Hartfelder, K. (2004) The initial stages of oogenesis and their relation to differential fertility in the honey bee (Apis mellifera) castes. Arthropod Struct. Dev. 33 , 431-442.

Tarpy, D.R., Delaney, D.A., Seeley, T.D. (2015) Mating frequencies of honey bee queens (Apis mellifera L.) in 
a population of feral colonies in the northeastern United States. PLoS One 10, e0118734.

Tozetto S. de O. (1997) Hormonelle Steuerung in der Entwicklung von Drohnen. Doctoral Thesis, Eberhard-Karls-Universität Tübingen, Tübingen, Germany.

Vollet-Neto, A., Koffler S, dos Santos, C.F. Menezes, C., Nunes, F.M.F., Hartfelder, K. Imperatriz-Fonseca, V.L., Alves, D.A. (2018) Recent advances in reproductive biology of stingless bees. Insectes Soc. 65, 201-212.

Zander, E. (1916) Die Ausbildung des Geschlechts bei der Honigbiene (Apis mellifica L.). Z. Angew. Entomol. 3, 1-74.

Publisher's note Springer Nature remains neutral with regard to jurisdictional claims in published maps and institutional affiliations. 